University of Nebraska - Lincoln

DigitalCommons@University of Nebraska - Lincoln

\title{
A Design for a Sustained Assessment of Climate Forcing and Feedbacks Related to Land Use and Land Cover Change
}

Thomas Loveland

Rezaul Mahmood

Follow this and additional works at: https://digitalcommons.unl.edu/hprccpubs

Part of the Atmospheric Sciences Commons, Climate Commons, Environmental Indicators and Impact Assessment Commons, Environmental Monitoring Commons, Fresh Water Studies Commons, Hydrology Commons, Meteorology Commons, Natural Resources Management and Policy Commons, Sustainability Commons, and the Water Resource Management Commons

This Article is brought to you for free and open access by the High Plains Regional Climate Center at DigitalCommons@University of Nebraska - Lincoln. It has been accepted for inclusion in HPRCC Personnel Publications by an authorized administrator of DigitalCommons@University of Nebraska - Lincoln. 


\section{A DESIGN FOR A SUSTAINED ASSESSMENT OF CLIMATE FORCING AND FEEDBACKS RELATED TO LAND USE AND LAND COVER CHANGE}

by Thomas R. Loveland and Rezaul Mahmood

Sustained assessment of the climatic impacts of land use and land cover change is essential.

AFFILIATIONS: LOVELAND-U.S. Geological Survey Earth Resources Observation and Science Center, Sioux Falls, South Dakota; MAHMOOD-Department of Geography and Geology, and Kentucky Climate Center, Western Kentucky University, Bowling Green, Kentucky

CORRESPONDING AUTHOR: Rezaul Mahmood, Department of Geography and Geology, Western Kentucky University, 1906 College Heights Blvd., Bowling Green, KY 4210I

E-mail: mahmood.ei@ametsoc.org

The abstract for this article can be found in this issue, following the table of contents.

DOI:10.1175/BAMS-D-12-00208.I

In final form I3 February 2014

(C)2014 American Meteorological Society
(2003), noted that land use and land cover (LULC) and its feedback is an important source of uncertainty within the climate system (Melillo et al. 2014). As a result, the report calls for a better understanding of this research theme and recognized it as a high priority within research goal 1 (Melillo et al. 2014). In the recent past, the NRC (2005) and a number of papers in the scientific literature also called for broadening the scope of how we assess climate change (e.g., McAlpine et al. 2010; Pielke et al. 2009). As a result, LULCC has been identified as an important climate forcing by the scientific community. Key research on biogeophysical and biogeochemical impacts of LULCC on climate can be found in Pielke (2001), Feddema et al. (2005), Bala et al. (2007), Denman et al. (2007), Bonan (2008), Shevliakova et al. (2009), Arora and Boer (2010), Hibbard et al. (2010), Brovkin et al. (2013), and Mahmood et al. (2014).

Thus, to prepare the United States for future climate change and variability, a sustained assessment of LULCC (both natural and human managed) and its climatic impacts need to be undertaken. To address this objective, this paper proposes a series of action items (Fig. 1). In addition, national-scale 
institutional capabilities are identified and discussed. Included in the discussions are challenges and opportunities for collaboration among these institutions for a sustained assessment. Ideally, international collaboration should also be pursued but this topic is beyond the scope of this discussion. Moreover, in this paper, references to climatic impacts of LULCC include both biophysical and biogeochemical components. Additionally, the discussion presented here is a follow-up work linked to the activities related to the U.S. National Climate Assessment, and it used selected examples from the United States and referred to the U.S. institutions. However, we suggest that many of these activities are global in nature and other nations have a comparable institutional setup. Hence, these discussions can provide important guidelines or points of discussions for "sustained assessment" for other nations of the world.

SUSTAINED ASSESSMENT OF CLIMATE AND LULCC CONNECTIONS. The goal of an ongoing assessment capability should focus on understanding and explaining how climate and LULCC influence each other now and in the future. Understanding the connections and consequences of LULCC and climate will require ongoing monitoring, the translation of LULC into parameters relevant to meteorological and climatological processes, and the assessment of the real impacts that climate and LULCC have on each other. To fulfill these overarching goals, an ongoing LULCC-climate assessment should address the following:

- What are the primary contemporary trends in LULCC that affect, or are affected by, weather and climate?

- Of these trends, which sectors and regions are most affected by weather and climate variability?

- Which types of land use (thus, related changes) and regions are most vulnerable to climate change, and what are the spatial and temporal dimensions of the processes that affect their vulnerability?

- How are land use practices adapting to climate change?

Assessment research and development needs to fulfill overarching goals. To address assessment goals and related specific questions (bulleted items above), research and development need to focus on a series of objectives that ensure assessment results that are credible and relevant. Some specific foundational objectives for an ongoing assessment capability include the following:
I) Improve understanding of the connections between LULCC and weather and climate (Fig. 1). For effective modeling and assessment of climate and LULCC forcings and feedbacks, research should be carried out that

a) Improves our current understanding of how LULCC and atmospheric interactions are linked at local to global scales. In this process, it should also identify tipping points and lags of LULCC impacts.

b) Validates these connections through an analysis of the historical record. Past changes could be identified in LULCC that are attributable to changes in climate in order to project future changes in LULCC that could result from changes in climate.

Both the climate and the human activities that result in LULCCs are complex systems (Liu et al. 2007) and can only be observed with limited direct observations. For understanding both systems and how they interact, it is necessary to undertake new modeling research. Land-Use and Climate, Identification of Robust Impacts (LUCID; Pitman et al. 2009) and phase 5 of the Coupled Model Intercomparison Project (CMIP5) can provide the initial building blocks. Currently, many of the modeling systems are applied to simulate the climate system with assumptions on how land cover patterns will change with time (Brovkin et al. 2006) or to model land cover change with assumptions on how climate will change with time (Sohl and Sayler 2008). A research objective that better couples these models needs to adopted, so that feedback between the systems can be incorporated.

Any given model may be most appropriate for addressing a limited number of questions. Hence, it may be necessary to use a suite of models to fully understand system behavior [e.g., LUCID experiments (Pitman et al. 2009; de Noblet-Ducoudré et al. 2012; Brovkin et al. 2013), CMIP5, the Agricultural Model Intercomparison and Improvement Project (AgMIP), and the Inter-Sectorial Impact Model Intercomparison Project (ISI-MIP)]. The models are calibrated using observational data in historical periods, and the calibrated models may be used to project into the future. The ultimate purpose of the data collection and model simulations includes learning and better understanding of system complexity and subsequently informing decision makers and the public about anticipated impacts on human and ecological systems (including agricultural, forest, wildlife, and human communities), so that activities to mitigate and to 
adapt to the changes can be planned and undertaken.

To provide input to climate and meteorological models, LULCC forecast models must be spatially explicit, provide a means to parameterize key landatmosphere interactions, and provide scenario-based forecasts for 50-100 years. There are several forecast models in use that can be used to project regional to national LULCC patterns into the future [e.g., FOREcasting SCEnarios of Future Land-Cover (FORE-SCE) by Sohl et al. 2010] that are being used for the U.S. Geological Survey (USGS) LandCarbon study on carbon management opportunities). However, none of the models provides more than rudimentary handling of climate model variables. The most viable future LULCC projections will be those based on well-defined and vetted scenarios. For example, these would be based on sound land change histories and consideration of the influences that key drivers including policy, economics, population, culture, and technology will have under changing climate conditions. This approach is being investigated by Sleeter et al. (2012) through downscaling of the Special Report on Emissions Scenarios (SRES) story lines to ecoregions across the United States based on the integrated use of future climate conditions, regional resource conditions (e.g., geology, soils, topography), land use history, and expert knowledge. This approach provides a consistent overall framework of plausible scenarios that is regionally relevant but also consistent with global perspectives and influences. The U.S. Environmental Protection Agency (EPA) Global Change Research Program's Integrated Climate and Land Use Scenarios (ICLUS) project has established scenarios broadly consistent with the global-scale Intergovernmental Panel on Climate Change (IPCC) SRES story lines of population growth and economic development (U.S. Environmental Protection Agency 2009). The EPA ICLUS forecast provides spatially explicit maps of housing density and the expansion of impervious surfaces based on SRES story lines.

Because the SRES story lines were developed for use by climate change modelers to develop projections of future climate, they represent a reasonable starting point for a LULCC and climate assessment in the United States. The USGS has also used SRES story lines to establish a nationally consistent library of future land change scenarios for use in addressing biological carbon sequestration opportunities (Zhu et al. 2010). The USGS effort addresses all major land cover types found in the conterminous United States, and the SRES story lines are being developed for the ecoregions of the country. The SRES story lines provide the broad-level boundary conditions in the United States, and historical land cover trends are used to establish the basis for future regional land changes.

The IPCC's Fifth Assessment Report (AR5) is providing new concepts that will improve the relevance of scenario story lines. The representative concentration pathways concept should improve the consistency of the links between LULCC by explicitly specifying sectoral emissions and air pollutants (van Vuuren et al. 2011). The shared socioeconomic pathways concept that combines these future radiative pathways with alternative socioeconomic development avenues should improve the relevance of scenarios and modeling results (O'Neill et al. 2014).

Improvements in land change forecasts should benefit from the current National Research Council (NRC) study on the needs and research for land change modeling (NRC 2014), which is an important step toward improving future LULC forecasts. This 
study was recommended by the U.S. Global Change Research Program (USGCRP) Land Use Interagency Working Group based on the LULCC science priorities specified in the 2003 Climate Change Science Program's science strategy (U.S. Climate Change Science Program 2003). The NRC study should provide a thorough review of the present status of spatially explicit land change modeling approaches, the maturity of scenario research, and describe future data and research needs so that modeling efforts can better assist the science, policy, and decision-support communities. In addition, we suggest that land use forecast efforts should address historical and projected land use mapping from aggregate demand, which is based on land use suitability, economic viability, hydrological resource availability, and costs of transformation. All of these activities should address the first three bulleted items.

II) Improve coupling of LULC states and conditions within meteorological and climatological models (Fig. 1). This will require the following:

a) The translation of LULC variables into quantitative parameters that directly relate to the physics and chemistry connected with the exchange of energy, water, momentum, and particulate between the land surface and the atmosphere.

b) The ongoing development of multiresolution LULC parameters (biogeophysical and biogeochemical) needed to improve the accuracy of climate model forecasts. This also involves the ongoing development of climate data records and essential climate variablesdatasets based on international standards that ensure relevant, stable measures needed to understand climate and climate impacts (Global Climate Observing System 2010).

c) Efforts to couple climate and LULC forecast models, so that the dynamics of each component are part of the modeling process.

d) Model intercomparability studies should be used to determine the strengths and weakness of different models and modeling approaches.

Over the years, significant progress has been made in model design (physics and chemistry) that can address LULCCs and their interactions with weather and climate (e.g., Hurrell et al. 2013; Skamarock et al. 2008). Subsequently, both regional- and global-scale modeling efforts have been undertaken to determine the impacts and interactions. However, it is evident that experimental design and modeling capabilities need further improvement.

A number of in situ and remote weather and climate observation platforms are currently available that can be used to identify signals of impacts of LULCC on atmospheric data. These include the U.S. Climate Reference Network (USCRN) and several high-quality regional mesonets (e.g., Oklahoma, Kentucky, and Nebraska Mesonets). The latter could be excellent platforms for regional- and local-scale signals. In addition, satellite data can be used in conjunction with the in situ observations when available.

The International Global Energy and Water Cycle Experiment (GEWEX) or the First International Satellite Land Surface Climatology Project (ISLSCP) Field Experiment (FIFE) are examples of large collaborative research campaigns in which many scientific organizations interact to achieve broad and integrative scientific goals. One such goal is to understand how land surface hydrology influences water availability and security (Trenberth 2011). One element of reaching the goal is to account for realistic land surface complexity, including human influences such as LULCC and urbanization. Water quality, including water temperature and nutrient loadings, is affected by human influences, such as industrial and power plant use (NRC 2001). The availability of water for human use and ecological systems will, in turn, be affected by ecosystem responses to projected changing climate. Extremes of weather can also cause water systems to be vulnerable. On the other hand, good management and governance can increase resilience.

A range of multiresolution geospatial land coverrelated datasets would cover a variety of analysis functions-for example, model parameterization, monitoring trend in land condition, disturbance detection, and impact evaluation. Earth observations from global daily polar orbiter instruments such as the National Oceanic and Atmospheric Administration (NOAA) Advanced Very High Resolution Radiometers (AVHRR), the National Aeronautics and Space Administration (NASA) Moderate Resolution Imaging Spectroradiometer (MODIS) and the NASA-NOAA Visible Infrared Imager Radiometer Suite (VIIRS) provide 250-1000-m-resolution observations that can be used to generate current land parameters for meteorological models (e.g., surface albedo, surface temperature, leaf area index, and land cover). The NASA MODIS land products provide an important source for parameter datasets covering national to global scales (Justice et al. 2002). These same data can also be used to monitor vegetation condition trends, ranging from weeks to years. The 
USGS vegetation drought response index (VegDRI) product is an example of a national weekly geospatial land condition product (Brown et al. 2008).

Higher-resolution land cover characteristics and land cover change data are needed to detect disturbances or land cover transformations from local to national scales and to evaluate the specific cover types that are affected by weather and climate variability. Local case studies may be needed to document and determine the pace of LULCC for climate assessment. A Landsat-scale (30-m resolution) dataset, such as the USGS-led National Land Cover Database (NLCD), is suited to this application (Fry et al. 2011). However, an operational assessment would require land cover information at a more frequent interval than NLCD (updated every 5 years), and in order to be more relevant for assessing the connections between LULCC and climate, the detection of LULCC as it is occurring is an appropriate goal. The planned U.S. Forest Service (USFS)-USGS Land Cover Monitoring System concept that would provide Landsat-scale annual land cover disturbance data is a stronger, potential long-term candidate (Lebow et al. 2012). Finally, geospatial land use data are needed to understand local- to national-scale social and economic impacts and mitigation opportunities. Sectoral products, such as USFS Forest Inventory and Analysis (FIA) data and National Agricultural Statistics Service (NASS) data from the U.S. Department of Agriculture (USDA), are useful, but the absence of spatially explicit national land use data remains an issue.

New data sources and analysis techniques that have been applied to land cover analysis could be extended to incorporate time series of both land surface and climate observations, and then could be used to analyze the interactions of LULCC and climate (Knorn et al. 2009; Huang et al. 2010; Kennedy et al. 2010; Roy et al. 2010). Knowledge of such interactions could be used to assess the feedbacks between the land cover and climate systems (including teleconnections) and be incorporated into the next generation of coupled LULC and climate models. These activities will be helpful to all four major overarching objectives.

III) Increase understanding of the relations between climate and LULCC impacts (Fig. 1). This would require understanding how

a) weather and climate variables affect various LULC types differently;

b) different landscape variables (e.g., ecoregions, topography, and land ownership) modify these relations; and c) LULCC and ecosystems respond and recover after disturbance events.

Specialties under various academic disciplines study LULCC and their interactions with weather and climate. Many of these groups have started to increase scholarly communications among themselves, which has enhanced the flow of knowledge in the recent years. Particular attention needs to be provided toward further interactions between natural and social sciences for improved understanding of broader context. It is also needed because human and natural systems are not only coupled but also these couplings could be diverse over spatiotemporal scales and organizational units (Liu et al. 2007). Since land use decisions are inherently local and individual, there is a strong need to understand the human context. However, as noted by Liu et al. (2007), globalization has begun to bring many coupled systems closer. As a result, interactions among various coupled systems, as they relate to LULCC, need to be considered.

Further concerted efforts to expand these collaborations between natural and social sciences are essential to achieve this objective and would provide maximum benefit to society. Land change science can play an important role in providing a venue for these collaborations. Whether focused on climate and LULCC or on human-caused geomorphic changes that confound the impacts of weather and climate disasters (Werner and McNamara 2007), land change science represents a foundational approach for understanding the interactions between human and environmental systems (Rindfuss et al. 2004; Turner et al. 2007). Because of the major impact of LULCC on a wide range of environmental (e.g., climate, ecosystems) and economic, cultural, social, and political systems, there is a strong need for interdisciplinary cooperation that spans meteorology, climatology, geomorphology, ecology, geography, and other social sciences.

IV) An assessment capability is needed that provides regular information update on the impacts of weather and climate conditions and climate trends on LULC and LULCC. Reporting should focus on providing a clear understanding of the economic (including infrastructure), social, and ecological impacts, and on the ways LULC changes in response to events and trends. Specific considerations should include:

a) Distinguishing between short- and long-term climate patterns and their impacts on LULC. 
This will allow decision makers at all levels to determine mitigation or coping mechanisms.

b) Establishing the capability to evaluate the impacts of extreme weather events on LULC, addressing the stresses on economic, social, and ecological systems.

c) Providing an explanation on how local and regional climate and LULC impacts affect national and global economic, social, and ecological systems.

d) Providing forecasts on the potential land use impacts because of weather events and climate trends. These should include information on mitigation options and coping mechanisms.

e) Describing how LULCC related to weather and climate affect social and economic systems (e.g., impacts on forest productivity, range health, shortened/lengthened growing seasons for crop production). This should include the impacts of climate-induced LULCC on people's livelihoods.

Regions that are currently experiencing rapid LULCC and other ecologically sensitive and vulnerable areas could be considered as candidates for mesonets for weather and climate monitoring, leading to better understanding of the pathways, mechanisms, and processes related to LULCC impacts on the atmosphere. Specifically, in addition to existing observation platforms, establishing weather and climate monitoring capabilities needs to be considered in some of the above-noted areas. This effort could be completed in phases.

The combination of LULCC and climate may contribute to assessment of impacts of the capability of LULC systems to provide future goods and services. To detect evidence of land improvement or degradation, defining regional reference conditions and identifying a reference site can be used to determine the deviation from a sustainable state (Stoddard et al. 2006). For example, Herrick et al. (2010) show how data from the Natural Resources Conservation Service (NRCS) National Resources Inventory (NRI), along with remotely sensed imagery, soil surveys, and climate models, can be used to stratify landscapes in a way that allows the definition of reference conditions based on the long-term ecological potential of the land. Deviation from the reference conditions indicated possible land degradation. Moreover, an Integrated Valuation of Ecosystem Services and Tradeoffs (InVEST)-like approach could be considered in this vein.

Although it is difficult to quantify the societal benefits of LULC practices and conditions, some research is providing a basis to understand these benefits by using more traditional measures of economic output. For example, Nelson et al. (2009) have developed a modeling tool to predict changes in ecosystem services, biodiversity conservation, and commodity production levels, and have applied the tool to the Willamette basin in Oregon.

V) Maintain an outreach capability (Fig. 1) that ensures rapid access to assessment inputs and outputs, interpretation of the results, and technical support for decision makers and scientists engaged in climate and LULCC issues.

For this purpose, the communication of results and applications services used in assessing LULC and climate is critical to ensure the effective use of data, models, and analyses. This should include engaging and involving stakeholders in decision tool design, so that it meets their needs. Partnerships with local residents would lead to the development of tools that are tailored to the particular needs of different stakeholder groups.

\section{AVAILABLE INSTITUTIONAL CAPABILI-}

TIES. A sustained assessment of LULCC and weather and climate connections would require the participation of a number of USGCRP department and agency members as well as academic and industry researchers. Key agency participants and contributions could include the following:

EPA - Land change scenario information, with an emphasis on the built-up environment

NASA-Land and atmospheric observation missions, land surface parameterizations derived from remote sensing, land cover and atmospheric research, and weather and climate modeling

NOAA-Meteorological and climatological expertise, atmospheric observations (including all types of atmospheric soundings), in situ instrument records, and weather and climate modeling

National Science Foundation-Research support, weather, and climate modeling, and participation of key observation networks, such as the National Ecological Observatory Network (NEON)

National Park Service and U.S. Fish and Wildlife Service-Communicating climate change science and impacts to citizens

USDA-A wide range of field measurements and datasets and assessments, including USFS FIA and forest cover products, NRCS NRI and soil survey data, National Agricultural Statistical 
Service annual crop area, and type data and agricultural census results

USGS-Land remote sensing, digital elevation model (DEM) data/products, land cover map products, land change scenarios, land change modeling and forecasts, in situ measurements (e.g., stream gauges), and climate and land use research

Academic institutions and industry-Extensive research capability in all aspects of LULCC and outreach infrastructure.

Other nations of the world could also adopt a similar approach to use available governmental, academic, and private sector resources to accomplish LULCC and climate-related sustained assessments.

The integration of federal capabilities will be challenging and will require a fresh approach. Beever and Woodward (2011a), for example, suggest that climate and land monitoring that effectively supports resource management might ideally be structured to address the actual spatial and temporal scales of relevant processes, rather than the artificial boundaries of individual land management units. It needs to be emphasized that assessment capabilities should include the means to evaluate the interactions of land use and management with climate change in a way that will help decision makers, including landowners, to mitigate or adapt to the changes. This would require general principles on how the management may need to adapt in the context of changing climate, rather than working from implicit assumptions on static climatic conditions (West et al. 2009). In particular, land managers and others may need to assess whether changes in climate would push formerly advantageous LULC conditions beyond the point that they provide the necessary goods and services. Future LULC management strategies may require methods that incorporate an evaluation of how climate and LULCC effects can combine to influence a wide range of social and economic benefits; public policy issues, such as the Endangered Species Act; and ecological factors, such as the migration of species, the shifting mosaics of wetlands, and disturbances on climate-biology relations. The mechanisms of ecological response need to be incorporated into the design of the monitoring systems (Beever and Woodward 2011b).

In summary, assessment and monitoring systems for understanding the changing relations between land use, land cover, and climate should make use of information from multiple scales of space and time. Field plot measurements of vegetation and land use properties, such as those from the USFS FIA program and the NRCS NRI and soil surveys, and the Oak Ridge National Laboratory-led AmeriFlux towers for detailed understanding of carbon dynamics; high-density atmospheric observation networks, such as mesonets in the ecologically sensitive regions and in the regions experiencing rapid changes; and long-term ecological research sites are needed for detailed understanding of processes. Remotely sensed data, particularly the Landsat time series integrated with higher- and lower-resolution data, can provide information on the spatial magnitude and directions of LULCC at multiple scales.

Integration of these data sources in models allows bridging the gaps in observation across space and time, and permits simulation of processes that are not directly observable. Testing of multiple scenarios may make it possible to separate the influences of different processes (e.g., land management compared to climate change or weather extremes), as they influence ecosystems and human activities. New methods of analysis, in which entire time series of images can be analyzed at once, provide new possibilities in classifying land cover change as it is occurring (Zhu et al. 2012). It is possible that the algorithms used in such analyses could be adapted to analyze joint time series of climate change, weather extremes, and land cover change to separate and investigate the interactions of these variables. Knowledge of such interactions could be included in coupled models of the climate and be used to forecast scenarios of future system behavior (e.g., tipping points). Such forecasts could help identify critical weaknesses in existing planning for mitigation and adaptation. The assessment system should include continued contact with groups that represent decision makers for urban and regional planning, agricultural and forest land management, biodiversity conservation, and ecological research, so that the models are sensitive to the types of policy choices that will be needed in the future. The research should be coordinated with national and international campaigns that have complementary interests, such as NEON, GEWEX, and the Global Earth Observation System of Systems (GEOSS). Data sharing among these groups and relevant idea development should be part of the activities.

The basic inputs needed for an operational LULCC-climate assessment capability are available, but some inputs will require improvements or changes in specifications in order to provide the timeliness and geographic coverage required. The real challenge will be the identification of a federal host to lead the assessment process. NOAA, the USDA, and the USGS are the logical candidates based on their mission 
objectives and current investments in climate and LULC. The U.S. Global Change Research Program provides an appropriate forum for discussion of the responsibilities.

CONCLUDING REMARKS. It is now well established that LULC forcing and feedbacks play an important role in the planet's climate system. Projected climate variability and change will challenge natural resources managers. Management challenges can be compromised when LULCC modifies or complicates strategies for managing climate change. As a result, maintaining the societal and ecological benefits drawn from the nation's land resources-land cover and land use-requires an integrated understanding of the bidirectional links between LULC (hence LULCC) and weather and climate. That understanding will likely come from an assessment capability assembled from the various USGCRP agency activities related to LULCC and climate change. In this paper, identification of the foundations of such a capacity-the state of science and the availability of the basic elements that might be included in an observing, measuring, monitoring, and assessment activity-has begun.

The foundation of climate-LULCC understanding and the scientific investigations addressing those bidirectional links are growing rapidly. Studies on the basic mechanics and processes governing the exchange of water and energy between the land surface and the atmosphere are maturing and being used in both experimental and operational forecasting. Years of land-atmosphere interaction research has led to significant maturity in the ability to analyze the role land cover plays in weather and climate formation. As a result, it is increasingly feasible to simulate local to regional LULC influences on weather and climate formation. The simulation of future LULCCclimate connections is more complicated because most future LULCC projections are not dynamically linked to climate and weather models. This is an area where more research and development are needed.

The national investments in Earth observations can provide the means to identify LULC stresses, to map the condition of LULC across the nation, and to determine how different regions are changing or adapting to different weather and climate conditions. While there is considerable capacity to provide nearreal-time monitoring of LULC responses to climate, there is currently no operational effort to monitor and evaluate those climate-driven LULCC.

A general conclusion is that the basic elements needed for monitoring and assessment exist, though not necessarily in a format that is optimized for the assessment of LULCC-climate impacts and feedbacks. The challenge will be the integration of capabilities, the enhancement of the different elements, and the maturing of assessment frameworks. Attention to the spatial and temporal scales of analysis; the geospatial framework for monitoring, assessing, and reporting LULCC-climate issues; the detailed specifications; and the validation of all inputs, outputs, and model assumptions would be needed. There are some obvious areas where improvements would be required. Most activities do not specifically address the climatic impacts of LULCC in Alaska, Hawaii, and the territories of the United States. Most observational capabilities are more adept in monitoring croplands and forests than cities, rangelands, and wetlands. Efforts to integrate in situ and remotely sensed data would require more attention. Improvements in model coupling would also be required. Perhaps most important for LULCC assessments is the improvement in geospatial representation of land use practices, which are needed to understand the extent of the social and economic aspects of climate impacts. In summary, the next steps are to move beyond independent case studies and a rich assortment of technical tools and data, to a designed, integrated framework for ongoing national assessments.

ACKNOWLEDGMENTS. The authors thank Jesse Winchester of Western Kentucky University for the preparation of Fig. 1 and Krista Karstensen of the U.S. Geological Survey for her intellectual contributions. Thanks also go to four anonymous reviewers for their valuable comments and suggestions, which helped improve this manuscript.

\section{REFERENCES}

Arora, V. K., and G. J. Boer, 2010: Uncertainties in the 20th century carbon budget associated with land use change. Global Change Biol., 16, 3327-3348, doi:10.1111/j.1365-2486.2010.02202.x.

Bala, G., K. Caldeira, M. Wickett, T. J. Phillips, D. B. Lobell, C. Delire, and A. Mirin, 2007: Combined climate and carbon-cycle effects of large-scale deforestation. Proc. Nat. Acad. Sci., 104, 6550-6555, doi:10.1073/pnas.0608998104.

Beever, E. A., and A. Woodward, 2011a: Design of ecoregional monitoring in conservation areas of highlatitude ecosystems under contemporary climate change. Biol. Conserv., 144, 1258-1269, doi:10.1016/j .biocon.2010.06.022. 
— within conservation areas, in a rapidly changing climate. Biol. Conserv., 144, 1255-1257, doi:10.1016/j .biocon.2011.04.001.

Bonan, G. B., 2008: Forests and climate change: Forcings, feedbacks, and the climate benefits of forests. Science, 320, 1444-1449, doi:10.1126/science.1155121.

Brovkin, V., and Coauthors, 2006: Biogeophysical effects of historical land cover changes simulated by six Earth system models of intermediate complexity. Climate Dyn., 26, 587-600, doi:10.1007/s00382-005 -0092-6.

— land-use and land-cover changes on climate and land carbon storage in CMIP5 projections for the twentyfirst century. J. Climate, 26, 6859-6881, doi:10.1175 /JCLI-D-12-00623.1.

Brown, J., B. Wardlow, T. Tadesse, M. Hayes, and B. Reed, 2008: The vegetation drought response index (VegDRI): A new integrated approach for monitoring drought stress in vegetation. GISci. Remote Sens., 45, 16-46, doi:10.2747/1548-1603.45.1.16.

Denman, K. L., and Coauthors, 2007: Couplings between changes in the climate system and biogeochemistry. Climate Change 2007: The Physical Science Basis, S. Solomon et al., Eds., Cambridge University Press, 499-587.

de Noblet-Ducoudré, N., and Coauthors, 2012: Determining robust impacts of land-use-induced land cover changes on surface climate over North America and Eurasia: Results from the first set of LUCID experiments. J. Climate, 25, 3261-3281, doi:10.1175 /JCLI-D-11-00338.1.

Feddema, J. J., K. W. Oleson, G. B. Bonan, L. O. Mearns, L. E. Buja, G. A. Meehl, and W. M. Washington, 2005: The importance of land-cover change in simulating future climates. Science, 310, 1674-1678, doi:10.1126 /science.1118160.

Fry, J. A., and Coauthors, 2011: Completion of the 2006 National Land Cover Database for the conterminous United States. Photogramm. Eng. Remote Sens., 77, 858-864.

Global Climate Observing System, 2010: Implementation plan for the Global Observing System for Climate in Support of the UNFCCC. World Meteorological Organization GCOS-138, 180 pp.

Herrick, J. E., V. C. Lessard, K. E. Spaeth, P. L. Shaver, R. S. Dayton, D. A. Pyke, L. Jolley, and J. J. Goebel, 2010: National ecosystem assessments supported by scientific and local knowledge. Front. Ecol. Environ., 8, 403-408, doi:10.1890/100017.

Hibbard, K., A. Janetos, D. P. van Vuuren, J. Pongratz, S. K. Rose, R. Betts, M. Herold, and J. J. Feddema,
2010: Research priorities in land use and land-cover change for the Earth system and integrated assessment modelling. Int. J. Climatol., 30, 2118-2128, doi:10.1002/joc. 2150.

Huang, C., S. N. Goward, J. G. Masek, N. Thomas, Z. Zhu, and J. E. Vogelmann, 2010: An automated approach for reconstructing recent forest disturbance history using dense Landsat time series stacks. Remote Sens. Environ., 114, 183-198, doi:10.1016/j .rse.2009.08.017.

Hurrell, J. W., and Coauthors, 2013: The Community Earth System Model: A framework for collaborative research. Bull. Amer. Meteor. Soc., 94, 1339-1360, doi:10.1175/BAMS-D-12-00121.1.

Justice, C. O., J. R. G. Townshend, E. F. Vermote, E. Masuoka, R. E. Wolfe, N. Saleous, D. P. Roy, and J. T. Morisette, 2002: An overview of MODIS land data processing and product status. Remote Sens. Environ., 83, 3-15, doi:10.1016/S0034-4257(02)00084-6.

Kennedy, R. E., Z. Yang, and W. B. Cohen, 2010: Detecting trends in forest disturbance and recovery using yearly Landsat time series: 1 . Land Trendr-Temporal segmentation algorithms. Remote Sens. Environ., 114, 2897-2910, doi:10.1016/j.rse.2010.07.008.

Knorn, J., A. Rabe, V. C. Radeloff, T. Kuemmerle, J. Kozak, and P. Hostert, 2009: Land cover mapping of large areas using chain classification of neighboring Landsat satellite images. Remote Sens. Environ., 113, 957-964, doi:10.1016/j.rse.2009.01.010.

Lebow, B., T. Patel-Weynand, T. Loveland, and R. Cantral, 2012: Land Use and Land Cover National Stakeholder Workshop. Tech. Rep. for the 2013 National Climate Assessment, 73 pp. [Available online at https://adapt.nd.edu/resources/1040 /download/of2012-1155.pdf.]

Liu, J., and Coauthors, 2007: Complexity of coupled human and natural systems. Science, 317, 1513-1516, doi:10.1126/science.1144004.

Mahmood, R., and Coauthors, 2014: Land cover changes and their biogeophysical effects on climate. Int. J. Climatol., 34, 929-953, doi:10.1002/joc.3736.

McAlpine, C. A., and Coauthors, 2010: More than $\mathrm{CO}_{2}$ : A broader paradigm for managing climate change and variability to avoid ecosystem collapse. Curr. Opin. Environ. Sustainability, 2, 334-346, doi:10.1016/j.cosust.2010.10.001.

Melillo, J. M., T. Richmond, and G. W. Yohe. 2014: Climate Change Impacts in the United States: The Third National Climate Assessment. U.S. Global Change Research Program, 841 pp. [Available online at http://nca2014.globalchange.gov/report.]

Nelson, E., and Coauthors, 2009: Modeling multiple ecosystem services, biodiversity conservation, commodity 
production, and tradeoffs at landscape scales. Front. Ecol. Environ., 7, 4-11, doi:10.1890/080023.

NRC, 2001: Grand Challenges in Environmental Sciences. National Academies Press, 106 pp.

— , 2005: Radiative Forcing of Climate Change: Expanding the Concept and Addressing Uncertainties. National Academies Press, 224 pp.

- , 2014: Advancing Land Change Modeling: Opportunities and Research Requirements. National Academies Press, 152 pp.

O’Neill, B. C., E. Kriegler, K. Riahi, K. L. Ebi, S. Hallegatte, T. R. Carter, R. Mathur, and D. P. van Vuuren, 2014: A new scenario framework for climate change research: The concept of shared socioeconomic pathways. Climatic Change, 122, 387-400, doi:10.1007/s10584-013-0905-2.

Pielke, R. A., Sr., 2001: Influence of the spatial distribution of vegetation and soils on the prediction of $\mathrm{cu}$ mulus convective rainfall. Rev. Geophys., 39, 151-177, doi:10.1029/1999RG000072.

— , and Coauthors, 2009: Climate change: The need to consider human forcings besides greenhouse gases. Eos, Trans. Amer. Geophys. Union, 90, 413, doi:10.1029/2009EO450008.

Pitman, A. J., and Coauthors, 2009: Uncertainties in climate responses to past land cover change: First results from the LUCID intercomparison study. Geophys. Res. Lett., 36, L14814, doi:10.1029/2009GL039076.

Rindfuss, R. R., S. J. Walsh, B. L. Turner II, J. Fox, and V. Mishra, 2004: Developing a science of land change: Challenges and methodological issues. Proc. Natl. Acad. Sci. USA, 101, 132976-132981, doi:10.1073 /pnas.0401545101.

Roy, D. P., and Coauthors, 2010: Web-Enabled Landsat Data (WELD): Landsat ETM+ composited mosaics of the conterminous United States. Remote Sens. Environ., 114, 35-49, doi:10.1016/j.rse.2009.08.011.

Shevliakova, E., and Coauthors, 2009: Carbon cycling under 300 years of land use change: Importance of the secondary vegetation sink. Global Biogeochem. Cycles, 23, GB2022, doi:10.1029/2007GB003176.

Skamarock, W. C., and Coauthors, 2008: A description of the Advanced Research WRF version 3. NCAR Tech. Note NCAR/TN-475+STR, 113 pp. [Available online at www.mmm.ucar.edu/wrf/users/docs /arw_v3_bw.pdf.]

Sleeter, B. M., and Coauthors, 2012: Scenarios of land use and land cover change in the conterminous United States: Utilizing the special report on emissions scenarios at ecoregional scales. Global Environ. Change, 22, 896-914, doi:10.1016/j.gloenvcha.2012.03.008.

Sohl, T. L., and K. Sayler, 2008: Using the FORESCE model to project land-cover change in the southeastern United States. Ecol. Modell., 219, 49-65, doi:10.1016/j.ecolmodel.2008.08.003.

— , T. R. Loveland, B. M. Sleeter, K. L. Sayler, and C. A. Barnes, 2010: Addressing foundational elements of regional land-use change forecasting. Landscape Ecol., 25, 233-247, doi:10.1007/s10980-009-9391-3.

Stoddard, J. L., D. P. Larsen, C. P. Hawkins, R. K. Johnson, and R. H. Norris, 2006: Setting expectations for the ecological condition of streams: The concept of reference condition. Ecol. Appl., 16, 1267-1276, doi:10.1890/1051-0761(2006)016[1267:SEFTEC]2.0 .CO;2.

Trenberth, K. E., 2011: Challenges in GEWEX. GEWEX News, No. 4, International GEWEX Project Office, Silver Spring, MD, 2-3.

Turner, B. L., II, E. F. Lambin, and A. Reenberg, 2007: The emergence of land change science for global environmental change and sustainability. Proc. Natl. Acad. Sci. USA, 104, 20 667-20671, doi:10.1073 /pnas.0704119104.

U.S. Climate Change Science Program, 2003: Strategic Plan for the U.S. Climate Change Science Program. Climate Change Science Program and Subcommittee on Global Change Research, 202 pp.

U.S. Environmental Protection Agency, 2009: Land-use scenarios: National-scale housing-density scenarios consistent with climate change storylines. Global Change Research Program, National Center for Environmental Assessment, Final Rep. EPA/600/R -08/076F, 137 pp.

van Vuuren, D. P., and Coauthors, 2011: The representative concentration pathways: An overview. Climatic Change, 109, 5-31, doi:10.1007/s10584-011-0148-z.

Werner, B. T., and D. E. McNamara, 2007: Dynamics of coupled human-landscape systems. Geomorphology, 91, 393-407, doi:10.1016/j.geomorph.2007.04.020.

West, J. M., S. H. Julius, P. Kareiva, C. Enquist, J. J. Lawler, B. Petersen, A. E. Johnson, and M. R. Shaw, 2009: U.S. natural resources and climate change: Concepts and approaches for management adaptation. Environ. Manage., 44, 1001-1021, doi:10.1007 /s00267-009-9345-1.

Zhu, Z., and Coauthors, 2010: A method for assessing carbon stocks, carbon sequestration, and greenhouse-gas fluxes in ecosystems of the United States under present conditions and future scenarios. U.S. Geological Survey Scientific Investigations Rep. 2010-5233, 190 pp. [Available online at http://pubs .usgs.gov/sir/2010/5233/pdf/sir2010-5233.pdf.]

—, C. E. Woodcock, and P. Olofsson, 2012: Continuous monitoring of forest disturbance using all available Landsat imagery. Remote Sens. Environ., 122, 75-91, doi:10.1016/j.rse.2011.10.030. 